\title{
Numerical Analysis of Effect of Bridge on Inundation Flow in the Kagetsu River on July 2017
}

\author{
Xiang Chen ${ }^{1, *}$, Ryuichi Hirakawa ${ }^{2}$, Terunori Ohmoto ${ }^{3}$ \\ ${ }^{1}$ Environment and Life Engineering, Graduate School of Engineering, Maebashi Institute of Technology, Maebashi, Japan \\ ${ }^{2}$ Department of Civil and Environment Engineering, Maebashi Institute of Technology, Maebashi, Japan \\ ${ }^{3}$ Faculty of Advanced Science and Technology, Kumamoto University, Kumamoto, Japan
}

Email address:

m1646502@maebashi-it.ac.jp (Xiang Chen), hirakawa@maebashi-it.ac.jp (R. Hirakawa), ohmoto@kumamoto-u.ac.jp (T. Ohmoto)

${ }^{*}$ Corresponding author

\section{To cite this article:}

Xiang Chen, Ryuichi Hirakawa, Terunori Ohmoto. Numerical Analysis of Effect of Bridge on Inundation Flow in the Kagetsu River on July 2017. International Journal of Environmental Protection and Policy. Vol. 6, No. 4, 2018, pp. 78-84. doi: 10.11648/j.ijepp.20180604.12

Received: November 5, 2018; Accepted: December 5, 2018; Published: December 6, 2018

\begin{abstract}
The flood behavior often affected by bridges, due to the accumulation of debris around bridge piers or the reduction of flow late. On the other hand, the effect of a bridge on a flood was not well studied. In this research, the simulation of the flood in the Kagetsu River in July, 2017 was conducted using 2D flow model in order to evaluate the effect of a bridge on the flood capacity, water level and flood scale. The flood behavior in residential area was also simulated. As a result, the bridge increased inundation velocity and inundation area, especially in the area around the bridge. When water level exceeds the height of bridge, flow discharge was limited by the area of bridge opening, which caused flow capacity decreasing. The stream force of flood was relatively strong at the area around the bridge.
\end{abstract}

Keywords: Heavy Rainfall, Flood Disaster, River-Crossing Structure, Numerical Simulation, Hita City, Kagetsu River Tsunami

\section{Introduction}

From 5th to 6th July, 2017, northern Kyushu area was hit by a heavy rainfall (Figure 1) [1]. The heavy rainfall was caused by a linear rain band, which was generated due to moist air flowed to the Baiu front. The Kagetsu River (a class-A river) overflowed due to this heavy rain, brought serious damage to the riverside area.

The Kagetsu River has steep gradient from the confluence with the Chikugo River to $8.7 \mathrm{~km}$ point toward upper reach. Its gradient is $1 / 256$ for $0 \sim 5.4 \mathrm{~km}$, and $1 / 96$ for 5.4 to $8.7 \mathrm{~km}$ from the confluence. The Kagetsu River does not have the enough capacity for floods due to its narrow channel. The maximum discharge of the Kagetsu River flood of July, 2012 was $1350 \mathrm{~m}^{3} / \mathrm{s}$, where its capacity was only $1200 \mathrm{~m}^{3} / \mathrm{s}$ [2]. Figure 2 shows the area where was damaged by this flood. The maximum discharge of Kagetsu River flood of July, 2017 was estimated to be $1700 \mathrm{~m}^{3} / \mathrm{s}[3,4]$.

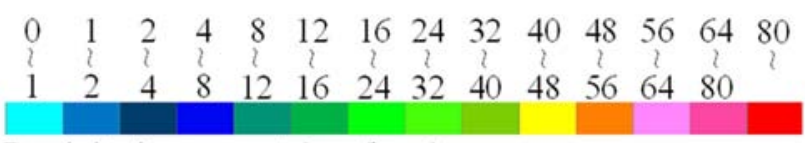

Precipitation amount ( $\mathrm{mm} /$ hour)

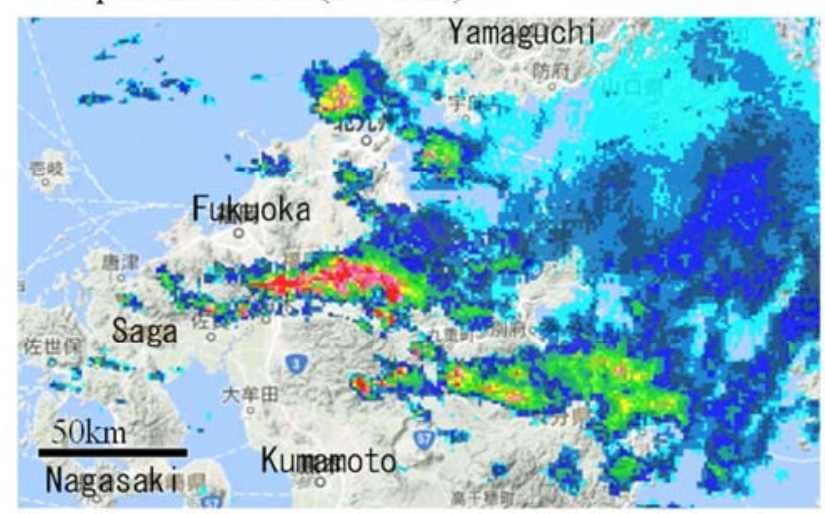

Figure 1. Distribution of rainfall precipitation. 


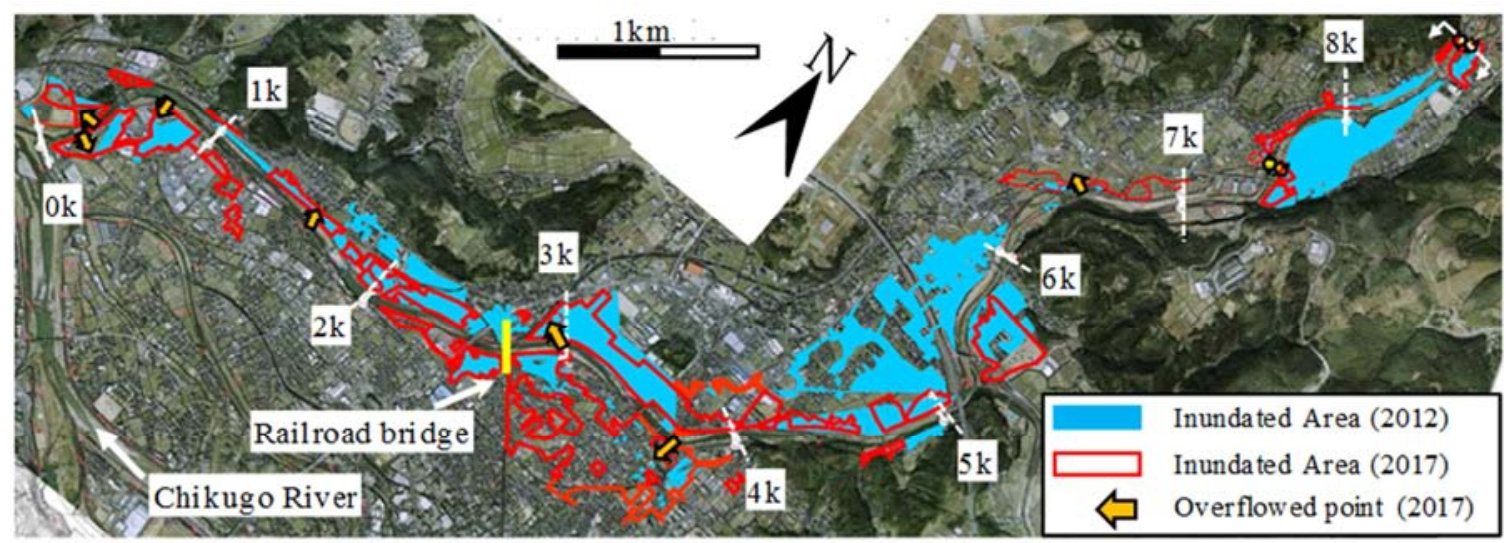

Figure 2. Inundated area in Kagetsu River flood.

Debris accumulation at a bridge often causes river overflowing. There are some previous researches about water level increasing caused by driftwood accumulation conducted in model experiments [5] or the distinct element method (DEM) [6, 7]. In the flood of July, 2017, water overflowed due to a congeries of wood debris around a pier of the railroad bridge of Kyudai main line. As the water level increased, driftwood accumulated on the railroad bridge (Figure 3). Finally, the railroad was swept away by the flood (Figure 4).

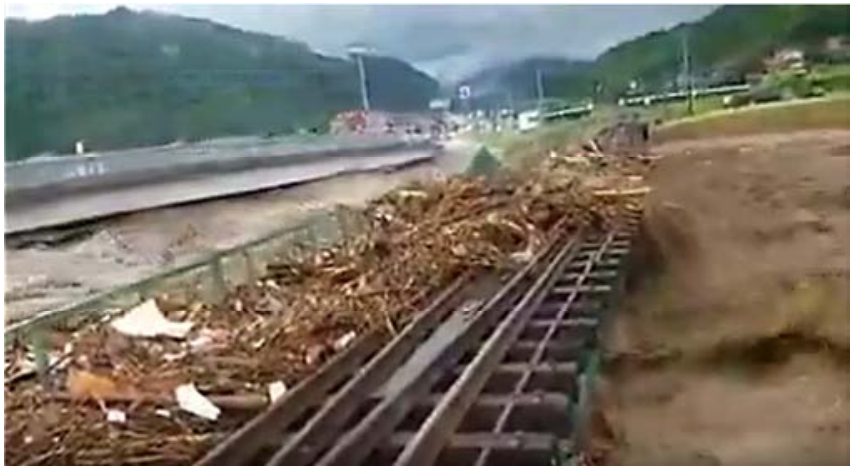

Figure 3. Wood debris accumulation on the railroad bridge.

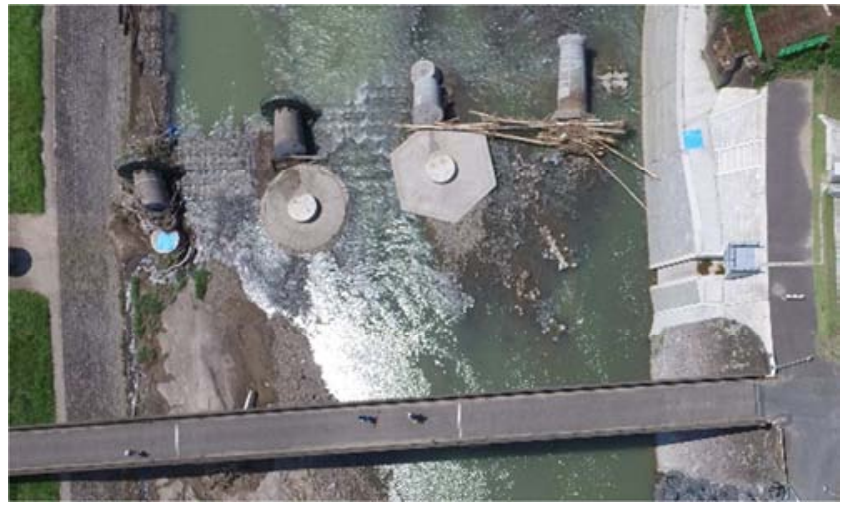

Figure 4. The collapsed railroad bridge.
In this research, the Kagetsu River flood of July, 2017 [8, 9] was simulated using inundation flow model, using the data of the flood of July, 2012 as a reference. The purpose of this research is to evaluate the effect of bridge on floods, and calculating the stream force of flood in residential areas.

\section{Methods}

\subsection{Flood Inundation Model}

In this research, a 2D planer inundation flow analysis of central area of Hita city was conducted. This analysis was conducted in Cartesian coordination. The flow discharge of the Kagetsu River was calculated from the confluence with the Chikugo River to $8.7 \mathrm{~km}$ point toward upper reach. In this analysis, the surveying data of channel cross section by Ministry of Land, Infrastructure, Transport and Tourism Kyushu Regional Development Bureau was used. The surveying data was obtained at intervals of 200 meters. The Manning's roughness coefficient of channel bed, flood plain, and vegetated area were set to $0.03 \mathrm{~m}^{-1 / 3} \mathrm{~s}, 0.04 \mathrm{~m}^{-1 / 3} \mathrm{~s}$, $0.05 \mathrm{~m}^{-1 / 3} \mathrm{~s}$, respectively. The discharge of upstream end was given according to the measured discharge from the observatory, which is located at $3.3 \mathrm{~km}$ point from the confluence. The discharge of downstream end was set to the total discharge of the Kagetsu River and the Chikugo River at the confluence. The time duration was determined as $1.0 \mathrm{~s}$. The equation of unsteady flow is [10];

$$
\begin{gathered}
\frac{\partial A}{\partial t}+\frac{\partial Q}{\partial x}=q \\
\frac{\partial Q}{\partial t}+\frac{\partial}{\partial x}\left(\frac{Q^{2}}{A}\right)+g A \frac{\partial h}{\partial x}+g \frac{Q|Q|}{C^{2} A R}=0
\end{gathered}
$$

where $x$ is distance coordination, $t$ is time, $A$ is channel cross section area, $Q$ is flow discharge, $h$ is water level, $q$ is discharge of inflow and outflow over banks. $C$ is roughness coefficient. $R$ is hydraulic radius. $g$ is gravitational acceleration. 


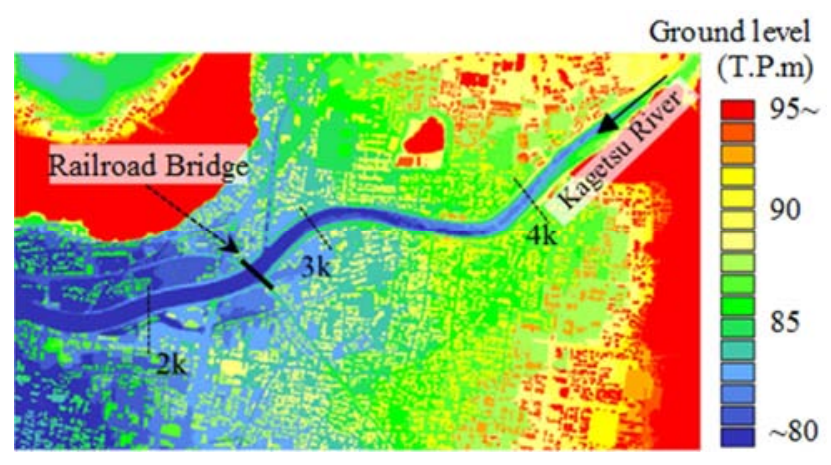

Figure 5. Topographic model of the residential area. a topographic model was prepared using ArcGIS according to $5 \mathrm{~m} \times 5 \mathrm{~m}$ meshed topographic data by Geospatial Information Authority of Japan. Buildings were described in $5 \mathrm{~m} \times 5 \mathrm{~m}$ meshed form and applied to the topographic data. Figure 5 shows the topographic model of the residential area. The heights of the buildings were set to $5 \mathrm{~m}$. Manning's roughness coefficient in the residential area was set to $0.10 \mathrm{~m}^{-1 / 3} \mathrm{~s}$. The time duration was determined as $1.0 \mathrm{~s}$.

Finite volume method (FVM) discretization was conducted for 2D planer inundation flow analysis in Cartesian coordination.

$$
\frac{\partial h}{\partial t}+\frac{\partial t}{\partial x}+\frac{\partial q}{\partial y}=0
$$

where $p, q$ are discharge fluxes of $x, y$ direction. $t$ is bottom face shearing force. $C$ is roughness coefficient. $s$ is water level. $h$ is water depth. $g$ is gravitational acceleration.

\subsection{Effect of the Railroad Bridge on Flow}

In this research, the effect of the railroad bridge of Kyudai main line on the flow behavior was evaluated. In 1D unsteady flow analysis, the head loss of flow through the bridge was evaluated using WSPRO method [11] (Figure 6). The height of the bridge is 83.156 (T.P.m). The water level measured at the observatory at 17:00 was 83.0 (T.P.m), and it had been still increasing. The bridge was swept away at around 17:30 [12] (the water level was 84.2 T.P.m). In this study, only the effect of the bridge was considered. The flow discharge through the bridge is;

$$
Q=C_{d} A_{2} \sqrt{2 g\left(h_{1}-h_{f 12}+h_{v 1}-h_{3}\right)}
$$

where $C_{d}$ is drag coefficient $\left(C_{d}=0.8\right) . A_{2}$ is cross section area of the bridge clearance. $h_{1}, h_{2}$ are water depth of upstream and downstream from the bridge. $h_{f 12}$ is Dancy friction factor. $h_{v 1}$ is velocity head.

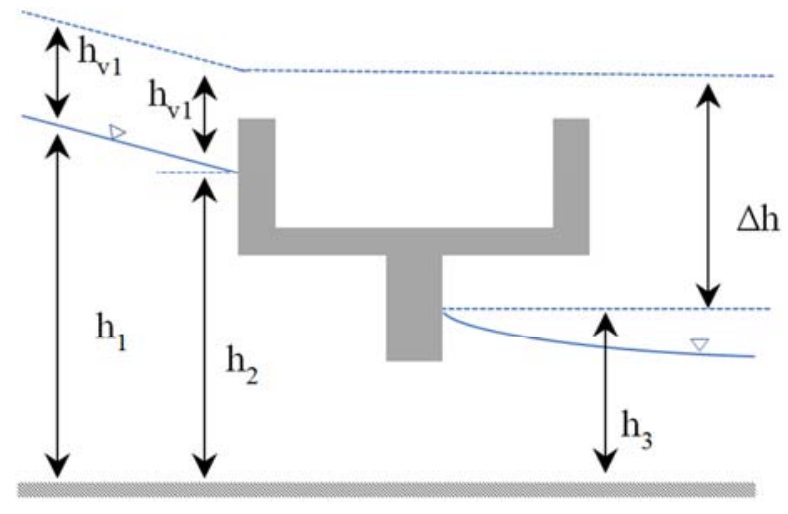

Figure 6. Bridge model.

\section{Results}

\subsection{Verification of Calculation Accuracy}

Figure 7 shows the water level by calculation and actual water level determined according to the trace of the flood. Both water levels are well matched, except upstream side. In upstream side, where has steep gradient, the water level by calculation is slightly higher than actual. Figure 8.shows the change of the water level at the observatory. Both water levels are well matched. However, the peak time of the flood by calculation was slightly longer than actual. This is due to flood water backed to the channel after the peak time.

\subsection{Inundation Behavior of the Flood}

Figure 9 and Figure 10 show the inundation depth and flux distribution calculated by $2 \mathrm{D}$ inundation flow analysis. The water level measured at the observatory at 18:20 was reached point $\mathrm{A}$ to the floodplain at 18:45. Because the floodplain elevation around the railroad bridge was relatively lower than other area, water also had overflowed from point $\mathrm{B}$ and $\mathrm{C}$. The water level measured at the observatory was reached to the peak $(4.5 \mathrm{~m})$ at 19:40. The floodwater flowed in the floodplain toward the south. Figure 9 (c) shows the flood inundated area due to this flood. There was no inundation at the left side floodplain near the section between $3.0 \mathrm{~km}$ point and $4.0 \mathrm{~km}$ point from the confluence. Hitarinkou high school, which is an evacuation spot, also was not inundated. The simulation result is well matched with the actual inundated area (Figure 2).

Figure 10 shows the flow velocity distribution by calculation. The flow velocity was over $1.0 \mathrm{~m} / \mathrm{s}$ at areas where overflow occurred (Figure 10 (a), (b)). Then the flow velocity decreased to $0.5 \mathrm{~m} / \mathrm{s}$ when flood reached its maximum inundated area. to $4.35 \mathrm{~m}$, which is danger level. Water had overflowed from 


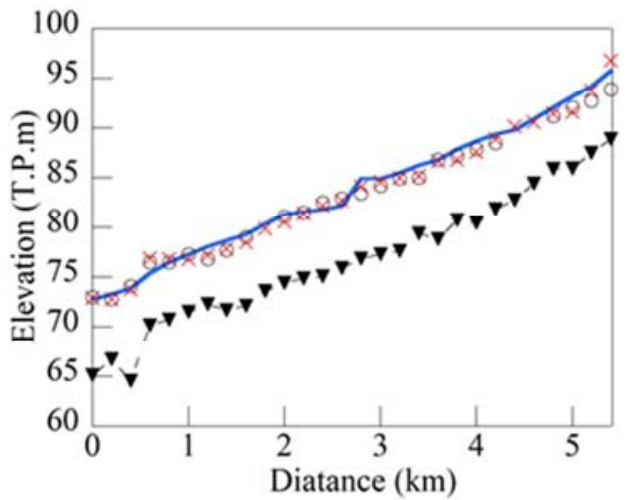

(a) downstream side (gradient $=1 / 256$ )

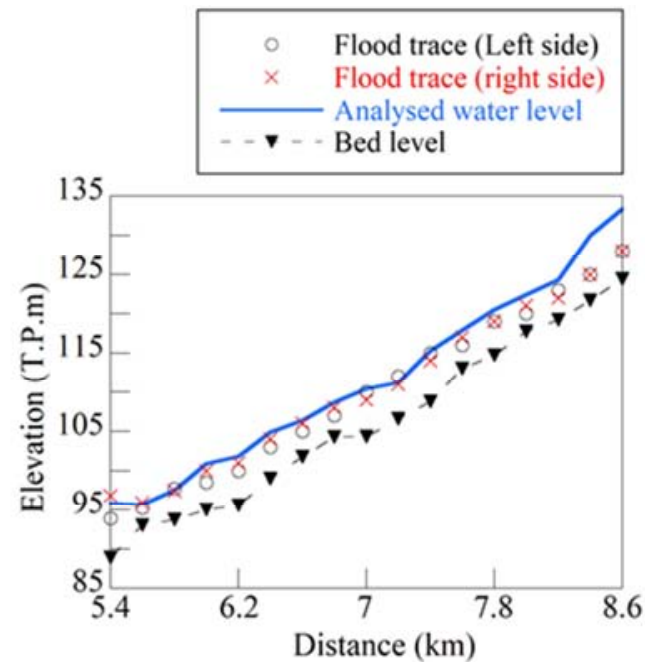

(b) upstream side (gradient $=1 / 95$ )

Figure 7. Comparison of water level.

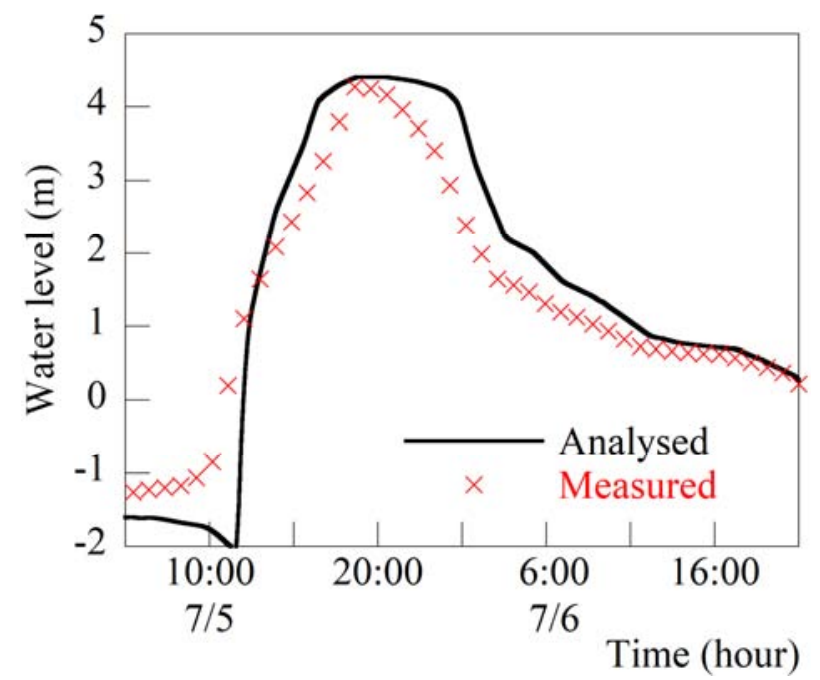

Figure 8. Water level at the observatory.

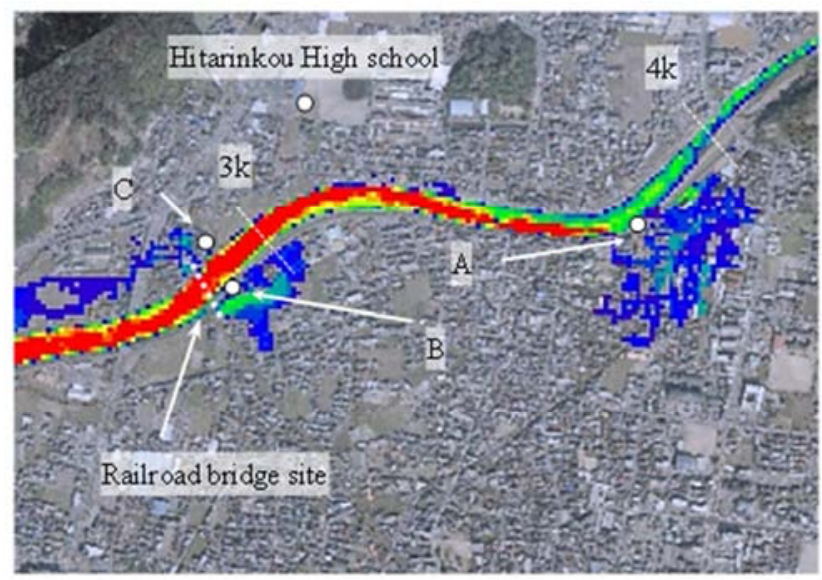

(a) $18: 45$

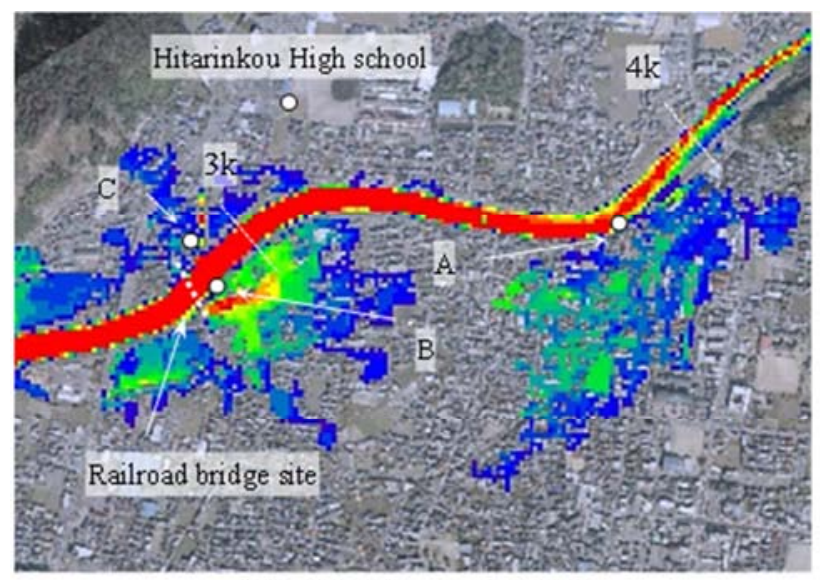

(b) $19: 40$ (flood peak time)

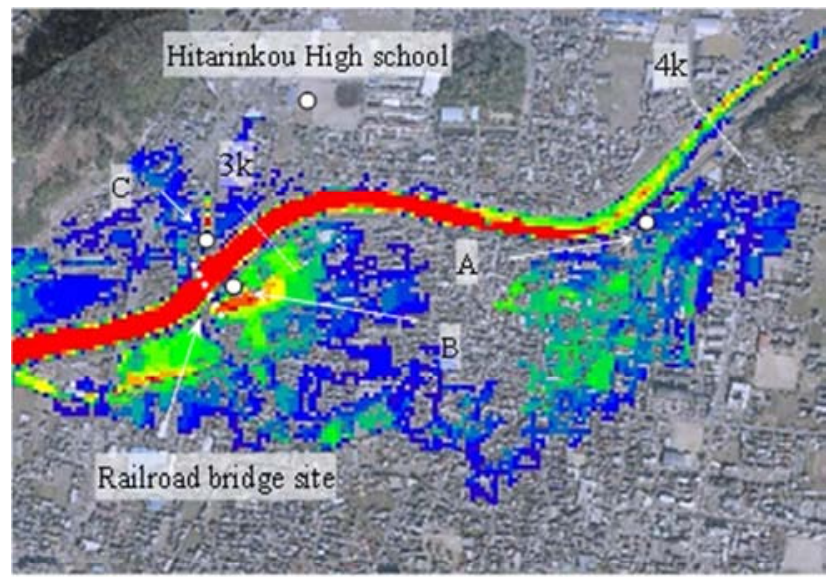

(c) 21:00 (maximum inundated)

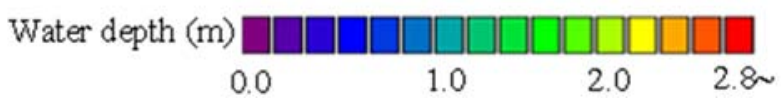

Figure 9. Inundation depth distribution by calculation. 


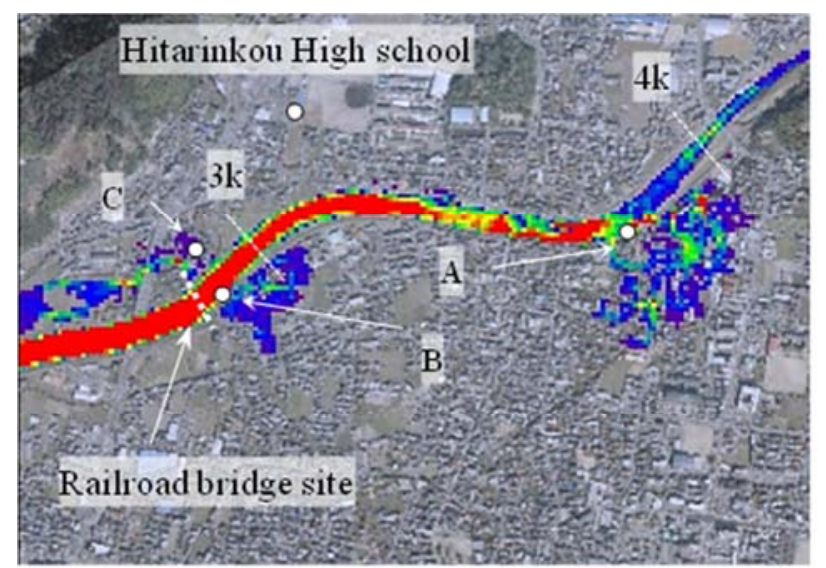

(a) $18: 45$

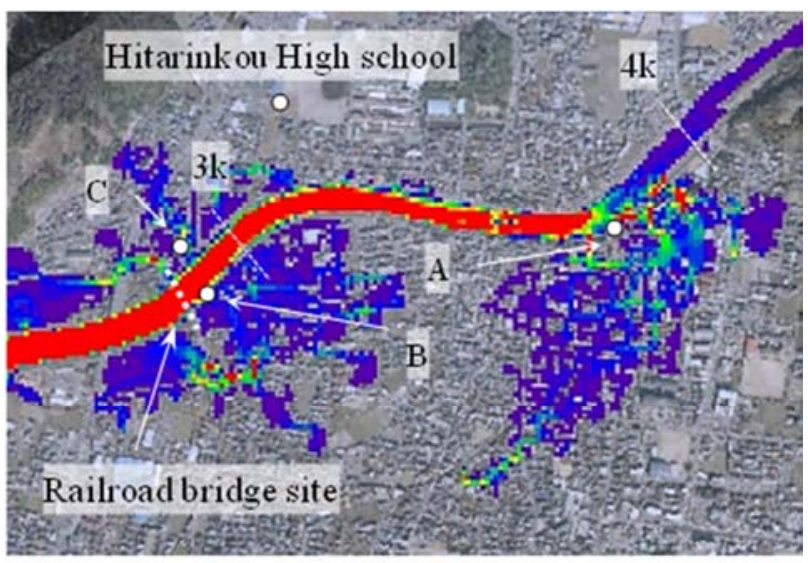

(b) 19:40 (flood peak time)

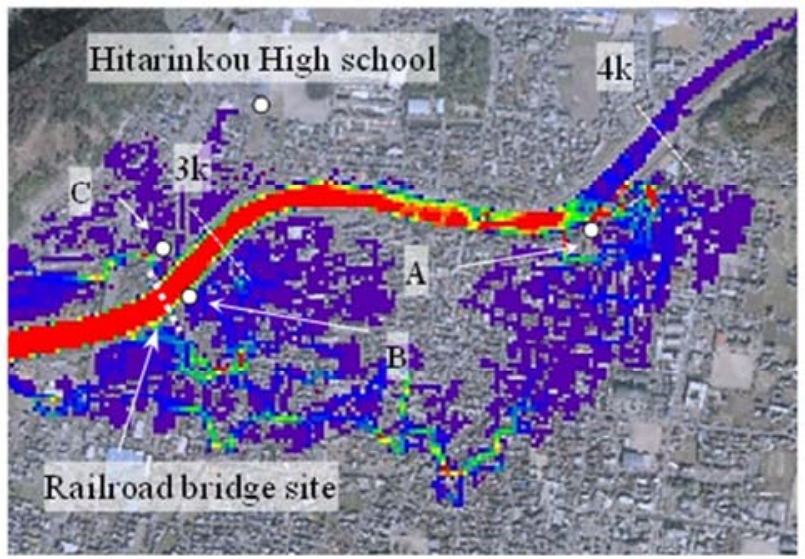

(c) 21:00 (maximum inundated)

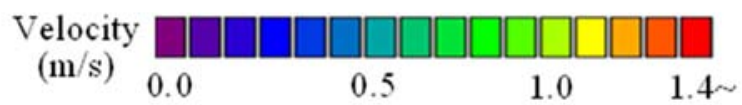

Figure 10. Flow velocity by calculation.

\subsection{Effect of Bridge on Flood}

When flood levels exceed heights of bridges, the flood behavior will be affected by bridges. Figure 11 shows effect of the railroad bridge on the water level at the $50 \mathrm{~m}$ point from the bridge toward upstream direction. The water level rose faster if the bridge exists. Moreover, the inundation behavior was also affected by the bridge; the overflow would occur earlier if the bridge exists. The overflow occurred at 16:50 with the bridge, and at 17:30 without the bridge.

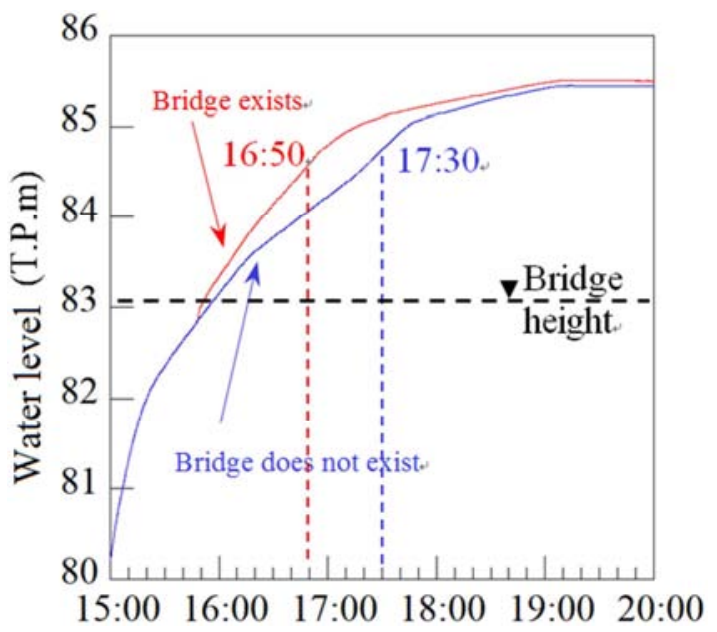

Figure 11. Effect of the bridge on water level.

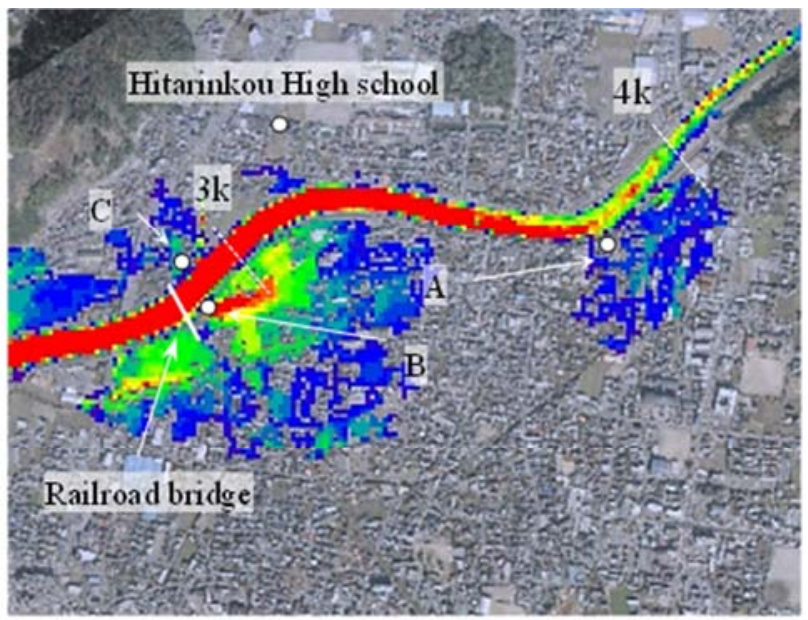

(a) $18: 45$

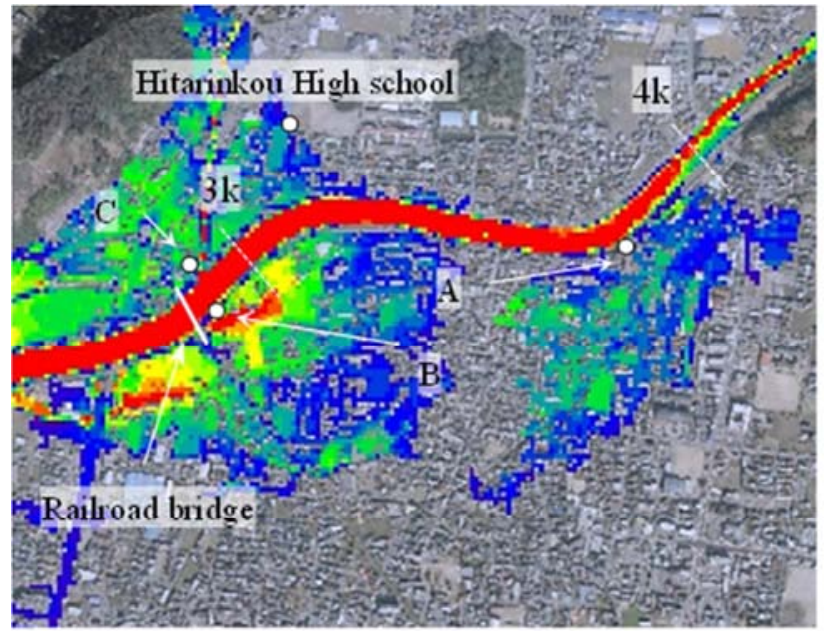

(b) 19:40 (flood peak time) 


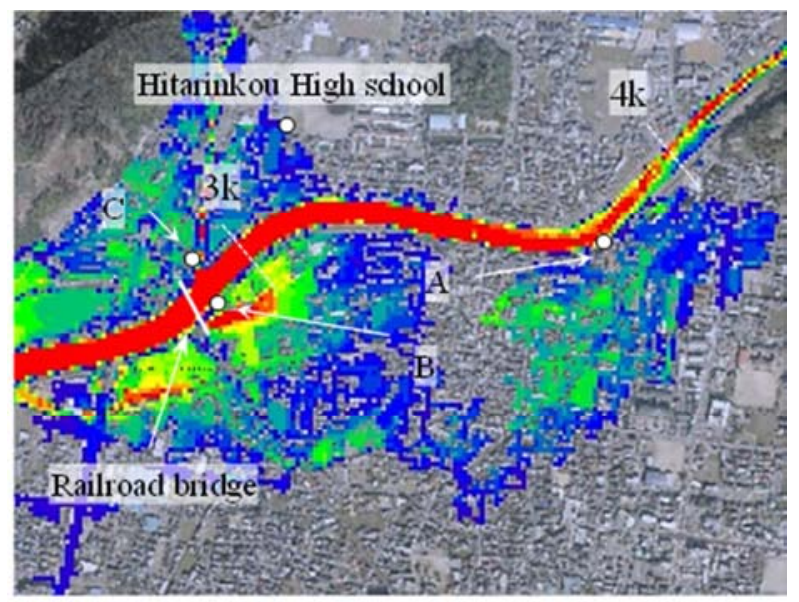

(c) 21:00 (maximum inunchated)
Water depth

(m) 0.0

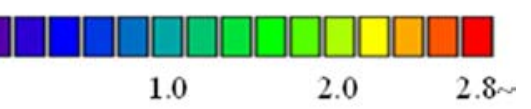

Figure 12. Inundation depth distribution (in case of the bridge had not been swept away).

Figure 12 shows the simulation of the distribution of inundation depth in case of the bridge had not been destroyed. Water had overflowed from point $\mathrm{B}$ and $\mathrm{C}$ at 18:45 (Figure 12 (a)). The inundation depth at point $B$ was over $1.4 \mathrm{~m}$. Figure 12 (b) shows the inundated area at the peak time of flood water level. Flood water spread at floodplain toward the north, and reached to Hitarinkou high school. The inundated area as shown in Figure 12 (b) and Figure 12 (c) were almost same, which means that the inundated area reached maximum at the peak time of flood water level.

Figure 13 shows the maximum stream force at the floodplain in case of the bridge had not been swept away. The stream force was calculated by following equation $[13,14]$;

$$
F=\frac{1}{2} C_{d} \rho u^{2} h
$$

where $C_{d}$ is drag coefficient $\left(C_{d}\right.$ was set to 1.0 in order to evaluate the maximum stream force). $\rho \mathrm{L}$ is water density. $u$ is flow velocity. $h$ is water depth.

As shown in Figure 13, the stream force was relatively strong near the point $\mathrm{A}$ or the railroad bridge, where overflows occurred. On the other hand, the stream force was much smaller than $20 \mathrm{kN} / \mathrm{m}$ and was not strong enough to sweep away buildings.
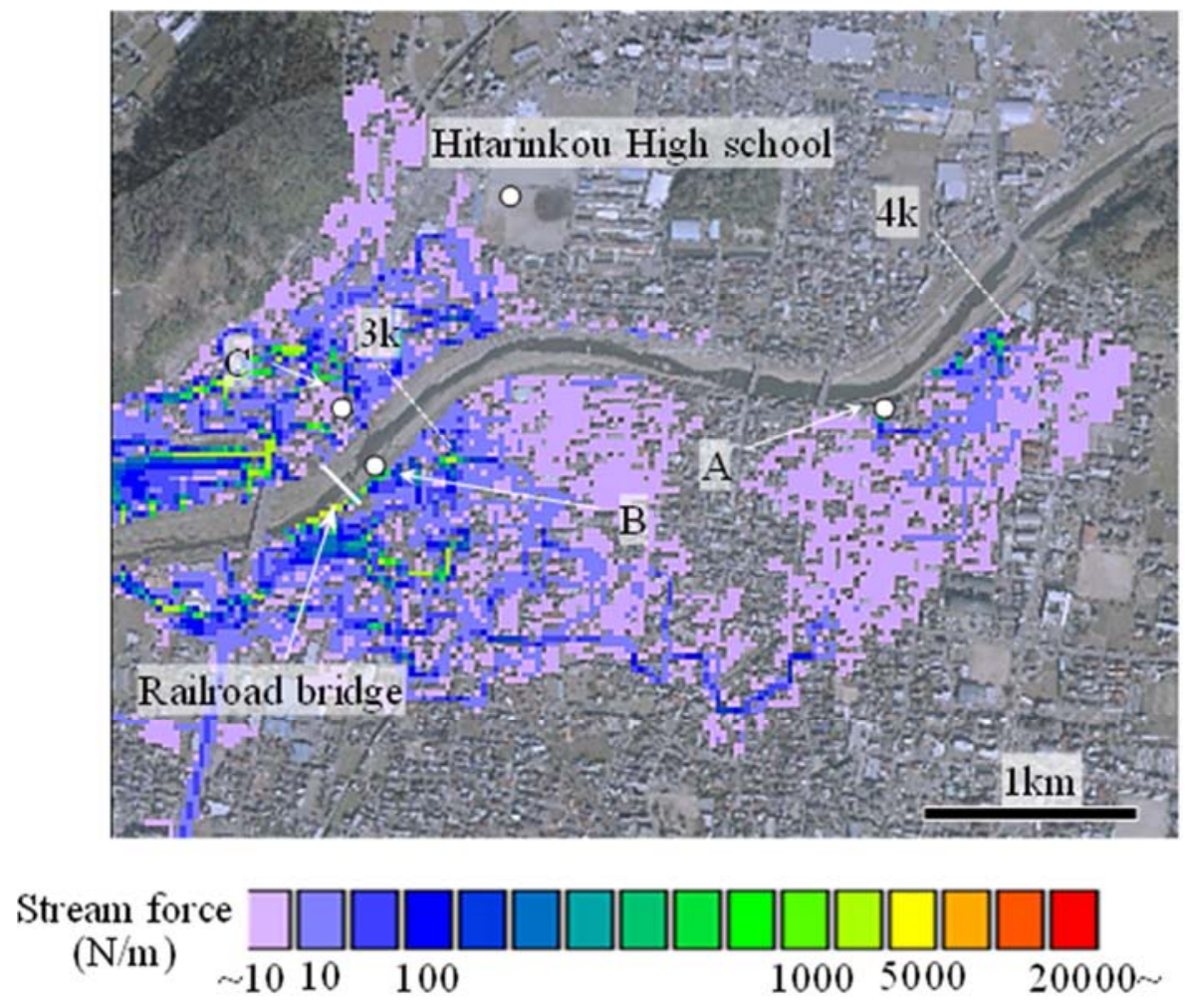

Figure 13. Maximum stream force distribution.

\section{Conclusion}

In this research, 2D inundation flow analysis and 1D unsteady flow analysis about the Kagetsu River flood of July, 2017 were conducted. In order to consider the flood flow behavior in residential area, the data of buildings was applied to the topographic data. Moreover, the effect of the bridge on the flood flow was discussed, and the maximum stream force at the floodplain was calculated. As a result;

1) The bridge caused the water level elevation and inundation at the area around the bridge, especially at the upstream side from the bridge.

2) The inundation behavior at the floodplain was strongly 
affected by the steep gradient of the floodplain. More flood water flowed into low ground, caused serious inundation

3) When the water level exceeded the bridge height, the flood capacity would be decreased, and led to water level increasing and overflows.

4) The bridge had a strong effect on inundation behavior. The inundated area in case of the bridge existed was much larger than that without the bridge.

\section{References}

[1] A. Kitamoto, National Institute of Informatics, Digital typhoon:Radar image (Zoom 8) | Heavy rain in the northern area of Kyushu(July, 2017)-Examples of heavy rain in the past, $\mathrm{http}: / /$ agora.ex.nii.ac.jp/digital-typhoon/heavy_rain/cases/20170 705/radar-8/.

[2] H. Yamamoto, T. Yamasaki, M. Yamamoto and H. Kobayashi, "Characteristcs of heavy rainfall and flood disaster in northern part of iota prefecture on july, 2012", Journal of japan society for natural disaster science, Vol. 32, No. 3, pp. 233-248, 2013.

[3] Ministry of Land, Infrastructure and Transport Kyushu Regional Development Bureau Chikugo River Office "Outline of Heavy Rain in Kyushu Northern Heisei July 2007,” July 28, 2017.

[4] M. Shige-eda, J. Akiyama, K. Okubo and H. Nakashima, "Numerical simulation of rainfull-runoff and flood inundation flows based on rainfall in the kagetsu river basin on Kyushu-houkubu heavy rain in 2017", Advance in river engineering, Vol. 24, pp. 451-456, 2018.

[5] S. Adachi, A. Daido, "Experimental study on washed timbers," Disaster Prevention Research Institute Annuals, Vol. 1, pp. 41-49, 1957.
[6] Y. Shimizu, K. Osada, and T. Takanashi, "Numerical simulation of the driftwoods behavior by using a dem-flow coupling model," Journl of japan society of civil engineers (Hydraulic engineering), Vol. 50, pp. 787-792, 2006.

[7] S. Katsuki, H. Shibuya, H. Ohsumi, and N. Ishikawa, "Simulation of real bridge disaster up with woody debris using 3-d dem," Journal of applied mechanics JSCE, Vol. 69, pp. $1-15,2013$.

[8] Civil Engineering Association Kyushu Northern Heavy Rain Disaster Investigation Team, "July 2012 Northern Kyushu Heavy Rain Disaster Report," Japan Society of Civil Engineers, 2012.

[9] T. Miyazaki, S. Fukuoka, and M. Uemura, "Study on variations and flooding flows of the july 2012 floods in the kagetsu river," Journl of japan society of civil engineers (Hydraulic engineering) B1, Vol. 71, pp. 1465-1470, 2015.

[10] Abbott, M. B: Computational Hydraulics: Elements of the Theory of Free Surface Flows, Ashgate Publishing Limited, 1992.

[11] US Army Corps of Engineers:A Comparison of One-Dimensional Bridge Hydraulic Routines from:HEC-RAS, HEC-2 and WSPRO, Hydrologic Engineering Center, 1995.

[12] S. Yano: Preliminary bulletin of Kyushu Northern heavy rain survey team 2017, 2017.

[13] Federal Emergency Management Agency:Guidelines for Design of Structures for Vertical Evacuation from Tsunamis, 2012.

[14] S. Kure, A. Hayashi, S. Moriguchi, T. Horiai, H. Tanaka, "Evaluation of probable maximum hydrodynamic force of flood inundation at the shibui river in September 2015", Advance in river engineering, Vol. 22, 2016, pp. 297-302. 